\title{
Target promotions: How to measure and improve promotional effectiveness through individual customer information
}

Received (in revised form): 20th October, 2005

\section{Cristina Ziliani}

is a senior research associate in retailing and a lecturer in direct, database and internet marketing at the Università degli Studi di Parma, Italy.

\begin{abstract}
This paper proposes a new approach to measuring the effectiveness of consumer promotions, enabled by individual customer information collected via loyalty cards. The paper begins by discussing the complexity associated with measuring promotional effectiveness and the limits of current methodologies, then sets out to demonstrate that a customer-focused approach to promotion measurement - as opposed to the current product-focused perspective - can expand the measurability of promotional effects in three dimensions:
\end{abstract}

- objectives - in that not only sales volume and market share effects can be tracked, but also customer-specific and assortment-wide effects;

- time - in that promotional effects can be monitored for longer periods of time and the fulfilment of long-term goals can be measured;

- space - thanks to geo-marketing analysis, sense can be made of the variability of promotional response in different retail markets, channels and outlets.

This allows for better promotion planning and marketing effectiveness, with consequences that extend beyond economic benefits for the retail company itself and reverberate on relationships with suppliers and cooperative promotion decisions.

Cristina Ziliani

Università degli Studi di

Parma

Facoltà di Economia

Via J. F. Kennedy 6, 43100

Parma, Italy

Tel: +39 (0)521 902012; Fax: +39 (0)521 032393

e-mail:

cristina.ziliani@unipr.it

\section{RELEVANCE OF PROMOTIONS}

Promotions are used extensively in marketing, and promotional expenditure has been slowly but steadily increasing worldwide over the past 20 years. ${ }^{1}$ Highly competitive market places compel marketers to increase promotional spending: in the USA, fast moving consumer goods (FMCG) manufacturers invest 25 per cent of their marketing budget in consumer promotions, ${ }^{2}$ up from 15 per cent in 1978. In Italy, promotional spending increased by 10 per cent in 2003 and even further in 2004 and 2005, following a dramatic slump in consumption $(-2.4$ per cent) and retailers' efforts to sustain sales.

The increased economic relevance of promotions is not necessarily accompanied by results: according to Information Resources, in Italy, despite a +1.6 per cent increase in promotional 
Table 1: More pressure does not mean more sales (Italy 2004)

\begin{tabular}{lllll}
\hline & Hypermarket & $\begin{array}{l}\text { Change over } \\
\text { previous year (\%) }\end{array}$ & Supermarket & $\begin{array}{l}\text { Change over } \\
\text { previous year (\%) }\end{array}$ \\
\hline Promotional pressure (\%) & 30.8 & +1.5 & 21.1 & +1.6 \\
Markdown (\%) & 24.3 & +0.5 & 24.5 & +0.8 \\
Effectiveness & 59 & -0.1 & 53 & -0.3 \\
\hline
\end{tabular}

Source: Information Resources

pressure, and +0.8 per cent increase in markdown, in the supermarket industry, the result in terms of sales has been a disappointing +0.3 per cent (Table 1$)$.

Despite their diminishing returns, promotions cannot be disposed of, as they are permanent competitive 'weapons' for retailers. Indeed, retailers and manufacturers are likely to increase promotional spending in the future.

Moreover, promotional strategies are evolving, due to the diffusion of a loyalty/retention culture among retailers. The new focus on retention shifts promotions from outside the point of sale to the inside, from mass media to direct media, from one-size-fits-all to cluster marketing, from traffic building to share-of-wallet building efforts. . $^{3,4}$

Promotional plans grow in complexity, as massive adoption of loyalty schemes makes it necessary to integrate continuity promotions with short-term price promotion.

Discussion on how to make this investment more effective is therefore necessary, and this paper aims to stimulate it.

The first goal of this exploratory research is to discuss the complexity of measuring promotional effectiveness and analyse the 'defects' of methodologies currently in use in the industry, such as those developed by ACNielsen and Information Resources Inc.

The second and main objective of the research is to propose a new customer-focused approach to promotion measurement, demonstrating that it can overcome the limits of current 'sales-based' methods, and expand the number of measurable objectives.

Finally, the paper will suggest implications that the adoption of a customer-focused approach to promotions might have for retailers, suppliers and vertical relationships; these implications provide stimuli for further research.

To address these goals, the following research methods were combined:

- theoretical discussion of the complexity intrinsic to promotion measurement, based on an extensive literature review; - interviews (from June to October 2004) with eight major Italian FMCG retailers and manufacturers, and with four market information multinationals - ACNielsen, Information Resources, Catalina Marketing Inc. and DunnHumby - to identify limitations of current methodologies employed for the measurement of promotional effectiveness;

- development and testing of new customer-focused measures on a real marketing database, provided by a major Italian retailer, and design of the blueprint for a decision support system aimed at assisting retailers in their choice of category and brand for promotional purposes;

- discussion of preliminary results with a selected group of five Italian retail managers. 
Table 2: An overview of promotional objectives

\begin{tabular}{lll}
\hline & Short term & Long term \\
\hline Sales-related objectives & Increase sales and turnover & Expand market share \\
& Sustain volumes & Consolidate market share \\
& Regain lost market share & Expand brand's customer base \\
& React to competitor's move & Increase exclusive use of brand \\
& Get rid of excess inventory & Create entry/mobility barriers \\
Customer-related objectives & Stimulate first trial of product & Build loyalty \\
& Stimulate repurchase & Permanently lift consumed quantity \\
& & per customer \\
& Increase quantity usually purchased & Increase exclusivity of use \\
& Increase frequency of purchase & Suggest new uses for product \\
& Focus customers' attention on brand & Modify brand positioning \\
& Up-sell to larger size of product & Support brand image \\
& Increase stock in home & Expand share of wallet \\
& Stimulate impulse buying & - \\
& Collect information about consumers & - \\
Increase trade inventory of brand & Increase number of stores carrying \\
& & brand \\
& Push product listing by retailers & Increase category share \\
& Increase visibility in store & - \\
\hline
\end{tabular}

Source: Adapted from Busacca and Mauri (1994)

\section{LIMITS OF CURRENT MEASURES OF PROMOTIONAL EFFECTIVENESS}

According to Busacca and Mauri, ${ }^{5}$ promotional effectiveness is defined as 'the degree of fulfilment of the goals pursued by the company by means of a specific promotional action over a given period of time'.

Measuring the degree of fulfilment is difficult for the following reasons:

- there can be more than one goal to a promotion (Table 2), and goals may go beyond a simple sales lift on the promoted item;

- such goals are seldom clearly stated, due to the tactical nature of promotions;

- promotional effects before (lead) and after (lag/stock up) the actual promotional period can pass unnoticed;

- promotions display intrabrand, interbrand, intracategory, intercategory and store switching effects that escape conventional measures;

- consumer promotions are run while other marketing activities, such as advertising and trade promotions, are taking place; increasingly, several types of promotions (continuity, price and targeted ones) are run at the same time, and respective effects are difficult to isolate;

- effectiveness is a 'jigsaw', in that it results from the combination of the effects of diverse promotional elements: promoted category/brand, target, promotional tool, type of incentive, depth of discount, redemption effort, timing, media, message, testing and so on.

Given such complexity, the problem of measuring promotional effects has usually been solved by limiting the analysis to the most immediate and measurable aspect of the phenomenon: the so called 'sales effect' - that is the increase in sales volumes (and values) generated by the promotion.

Three common methodologies are used - alone or combined - to measure the 'sales lift':

- incremental sales; 
- variation of market share;

- redemption.

The incremental sales method is the commonest: ACNielsen and Information Resources established long ago their own methodologies to calculate the 'baseline' (ie sales that would occur anyway, not attributable to specific marketing activities) and hence determine promotional lift. Following interviews with Italian companies employing those methodologies, and with ACNielsen and Information Resources, who developed them, such methods were found to suffer from several defects, as listed below.

- Assumptions regarding the actual presence of a promotion: Based on the detection of price variations over a four-week period, analysts assume that a promotion is being run when a 10 per cent difference (for ACNielsen, 5 per cent for Information Resources) in price level per item is spotted. The two thresholds suggest that the two companies account for a different number of promotions, resulting in different 'universes'. Moreover, promotions are not monitored in all stores belonging to ACNielsen and Information Resources panels, hence limiting the extensibility of the results to the market (market share method).

- Absence of 'promotion-free' weeks for certain categories: The baseline calculation requires sales data from 'promotion-free' weeks. However, some categories where promotional pressure is very high never experience a promotion-free week during the year, forcing analysts (when calculating the baseline at category level) to make up a 'mock' promotion-free week by adding sales data from different promotion-free weeks for each item belonging to the category.

- Post-promotion effects are only monitored in the short term, typically over three- or six-week periods: Such time spans are standardised and are often shorter than the real repurchase cycle for the item, therefore distorting estimates of lead and stock-up effects and failing to capture medium- and long-term effects of promotions. This is a 'short-sighted mistake' made by data users (manufacturers and retailers looking at the data), rather than a pitfall of the methodologies. Market information companies, if requested, can supply customers with longer time series for analysis;

- Intrabrand, interbrand, category and store switching effects almost entirely escape measurement: This is the most notable defect of sales-based methods, and the most relevant for retailers, whose goal with promotions is to sell an assortment, rather than single stock keeping units, brands or categories. Switching effects can only be tracked and understood when there is a customer perspective to promotional analysis, by looking at shopping baskets over time.

The 'variation of market share' method, building on the incremental sales method, displays the same pitfalls and will not therefore be discussed here.

The 'redemption' method, typically used for coupons, is similarly faulty, in that the mere amount of redeemed coupons is no evidence of effectiveness per se. For example, a redemption rate of 40 per cent would, at first glance, lead to the assertion that the promotion was a success. But what happens when a closer look at the purchase records of those customers who took advantage of the promotion reveals that it was mainly customers loyal to the promoted brand (those who would have purchased anyway) who redeemed the coupon, while no new customer was attracted to 
the brand and no light consumers were persuaded to speed up their repurchase cycle and buy more? Is the promotion still regarded as effective? The importance of setting explicit promotional goals beforehand, and expressing them in terms of customer behaviour, not simply in terms of sales/volumes/number of coupons becomes evident.

\section{A NEW CUSTOMER-FOCUSED APPROACH TO PROMOTION MEASUREMENT}

When they were first introduced, scanners produced a major breakthrough in marketing and sales measurement. Before scanners, less reliable, patchy ex fabrica data were used. Almost 30 years later, it is not surprising that the dominating approach to promotional measures is sales driven; nonetheless, a new era for marketing measurement is coming, ushered in by a different technology: the customer database.

The third goal of this paper is to illustrate how individual demographic and behavioural customer information, such as that collected by loyalty cards, can be used in conjunction with scanner (sell-out) data to:

- overcome the limits of current sales-based methods;

- measure the degree of fulfilment of customer-specific, long-term and assortment-wide promotional objectives;

- create a knowledge repository which, if leveraged, can help to design better promotions.

The following discussion is based on analysis of the customer database of an Italian retail chain, and on the outcome of interviews. The findings were validated by means of a discussion with a group of five retail marketing managers.

\section{Overcoming the limits of 'sales-based methods'}

We mentioned earlier that in addition to sales-related objectives, a wide range of customer-related and trade-related objectives can also be envisaged for promotions. As far as customer-specific objectives are concerned (Table 2), loyalty data allow for a substantial advancement in measurability. Not only is the sample significant (the database often contains more than one year of purchase behaviour data for thousands of customers), but data reflect actual behaviour and are timely - a relevant fact, especially for promotion planning, if one considers that in FMCG preferences change quickly.

Most notable is the fact that, by identifying customers who took advantage of a promotion, it is possible to quantify fulfilment of specific objectives, such as the extent to which the promotion resulted in first trial, repurchase, sales subtraction from other brands/categories/stores and so on, as shown in Figure 1. Here, the information provided by the incremental sales method (the 'lift') is compared with that provided by the decomposition of the lift according to the customer segments who took advantage of the promotion (see pie chart in Figure 1). The generic increase in sales can be attributed to new customers (1 per cent), switchers (48 per cent), customers loyal to promoted brand (35 per cent), light consumers who were persuaded to buy more (10 per cent) etc, providing the retailer and the manufacturer with a more satisfactory understanding of the promotion's effects. It is worth noting that retailers can keep such additional insight to themselves, or share it with 


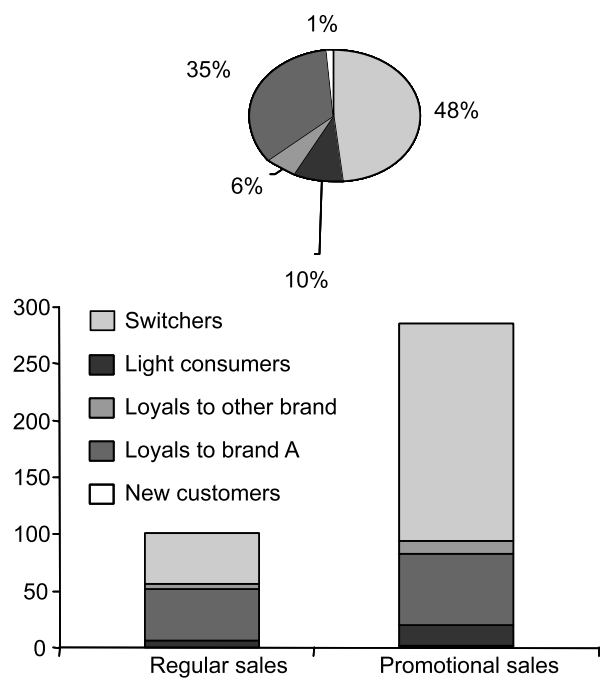

Figure 1 Measuring customer-specific objectives 'hidden' under the veil of promotional lift

the partner manufacturer, depending on the promotional agreement and the relationship.

Sales-based methods typically measure short-term promotional effects. With the new approach, the group of customers who bought during the promotion can be monitored over a much longer period of time. This enables companies to verify the long-term effects of the promotion: did consumers only buy the promoted good once, or did they repeat the purchase after the promotion was over? Have they become loyal to the promoted item or did they go back to their favourite brand, and so on (see Figure 2). Here, the lines show how the promoted items performed over a three-month period after the promotion, compared with the category they belong to: the increase in category share 'held' in the long term, in terms of volume, value and number of customers.

Individual customer purchase histories, moreover, enable the calculation of 'real' product purchase cycles, which can be used to determine the appropriate time span for measurements of effectiveness, and better estimates of lead and lag effects. In fact, it is often found that manufacturers' assumptions over purchase frequency for their products - typically derived from market research - differ from actual behaviour. Moreover, frequency is a 'learned behaviour' and it can differ widely from store to store depending on the promotional activity adopted (ie the promotional pattern in certain stores might have trained customers to 'wait for sales').

\section{Capturing switching effects}

As mentioned above, retailers are most interested in understanding the cross-elasticity of product demands, as they are continuously using promotions to support sales of the whole assortment of goods. By looking at shopping baskets, it is possible to monitor the impact of promotional actions not only on the promoted items, but most notably on other brands, categories, customer segments and stores. It is possible to establish how closely one product/brand/category/store is a substitute for another, with clear implications for pricing, merchandising, store layout and future promotions.

Table 3 shows substitution dynamics in 
Share of promoted items over time

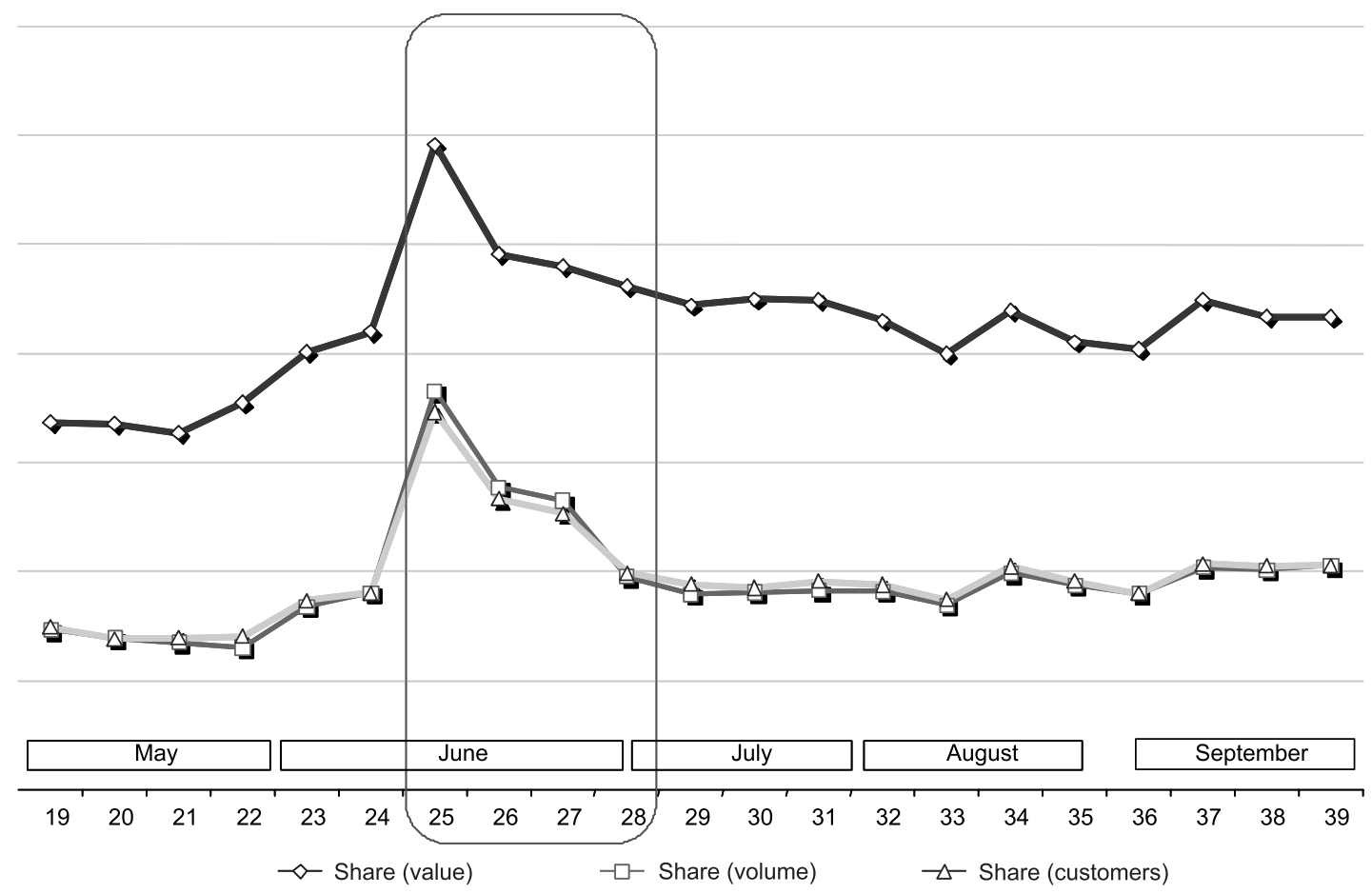

Figure 2 Tracking longer term effects of promotions

Table 3: Measuring variation of intracategory brand share over one year

\begin{tabular}{lllll}
\hline & $\begin{array}{l}\text { Category share } \\
\text { when SMA } \\
\text { is promoted }\end{array}$ & $\begin{array}{l}\text { Category share } \\
\text { when KRAFT } \\
\text { is promoted }\end{array}$ & $\begin{array}{l}\text { Category share } \\
\text { when } \\
\text { SMA + KRAFT } \\
\text { are promoted }\end{array}$ & $\begin{array}{l}\text { Category share } \\
\text { over year } \\
\text { (mean) }\end{array}$ \\
\hline SMA share & 50.5 & 35.0 & 49.8 & 42.0 \\
KRAFT share & 20.0 & 44.3 & 26.0 & 31.0 \\
CALVE share & 29.5 & 20.7 & 23.7 & 27.0 \\
\hline
\end{tabular}

Source: Catalina Marketing Inc.

the mayonnaise category over a one-year period. In the right-hand column it is possible to read the average category share of each brand during the year. The other columns show what happens to each brand's share when one or more brands are promoted - that is, which brands are more affected when others become more attractive to customers. This intracategory switching analysis, based on shopping baskets, can be extended to include substitute categories and cross-tabulated with customer segments. For example, a retailer might want to explore how the 'top' segment of the customer base reacts to promotions, or how the 'deal conscious' segment - that is, the group of customers who are most interested in promotions - welcomes a specific action.

Geo-marketing analysis can help to track the behaviour of customers who switch stores within the same chain for promotional reasons, and, most notably, it can also help to put the word 
'effective' into perspective. Indeed, the 'degree of fulfilment' of any promotional objective can be labelled as satisfactory (or not) only if it is compared with the promotion potential of the category and brand - a concept well known to retailers - but also the promotional potential of the area (the number, spending levels and preferences of customers in the target area affect promotional results). It emerged from the interviews that so far this geographical aspect of promotional potential has not been taken into account for promotional decisions and evaluations.

\section{Creating more effective promotions by leveraging the promotional knowledge base}

This returns to the statement that effectiveness results from the combination of diverse promotional elements: promoted category/brand, target, promotional tool, type of incentive, depth of discount, redemption effort, timing, media, message, testing and so on. In order to improve the design of future promotions, it would therefore be very useful to keep track of past promotional decisions regarding each element, and their impact/result, by appending information to the database. This study found that, due to the tactical nature of promotions, their frequency and the sheer quantity of data that needs to be processed and set aside, promotional information other than sales volumes is seldom fed into marketing information systems.

Effectiveness, however, can be 'built' into promotions by learning from accumulated knowledge. Take, for example, the decision regarding what category to run the promotion in: the customer database can serve as an excellent information base to choose the appropriate category, avoiding the trap of me-too decisions (let's promote the same category as the competitors...) and at the same time serving the retailer's own objectives, not only the partner manufacturer's.

When a customer-focused approach to promotions is adopted, new measures and indicators that help to refine decisions can be constructed. As an example, a prototype of category/brand choice decision support system for promotions was created (Figure 3); this reveals differences in potential effectiveness for categories that at first sight seemed equivalent. The value of information such as the percentage of 'gold' customers who buy the category, the intensity of brand switching, the promotional proneness of customers shopping within the category is self-evident. This information is all made available by the new approach.

Effectiveness can be increased ex ante also via segmentation and appropriate targeting of the customer base: segmentation criteria should be defined according to promotional objectives. If the goal is to increase share of wallet or brand loyalty, for example, customers should be segmented and targeted accordingly. One of the most interesting applications, in this respect, is segmentation of customers according to promotional behaviour, an exercise that Tesco has been carrying out successfully on their customer database, as DunnHumby explained during the interview. Needless to say, to exploit this segmentation to the full, communicate directly with selected segments and target them with ad hoc promotions, there needs to be a system in place. Loyalty card databases can help, if information such as address, telephone number and e-mail address of customers have been captured and updated over time. For a discussion of European retailers' adoption of targeted 


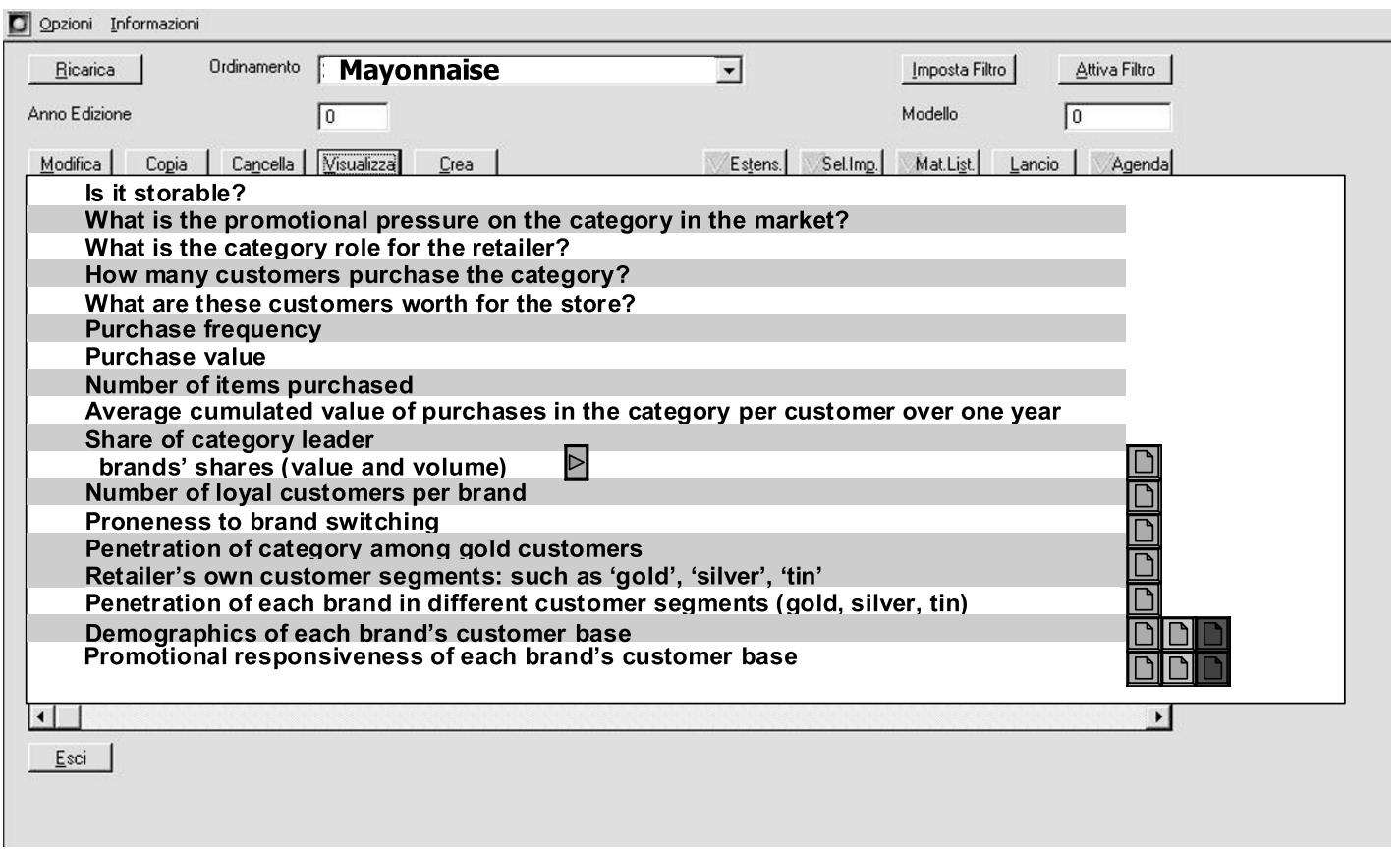

Figure 3 A customer focused decision support system to assist choice of category and brand for promotions

promotions and direct media see Ziliani and Bellini (2004). ${ }^{6}$

\section{Impact on vertical relationships}

With this information, and new measures and tools, retailers can take a more mature and discerning approach to promotional decisions, especially when it comes to choosing between deals offered by different manufacturers. Data about the category/brand potential and past promotional results can be quickly accessed (as shown in Figure 3) and negotiation influenced accordingly. It is likely that, in the future, a retailer's evaluation of prospective partners will incorporate elements such as the ability to discuss and set customer-specific and long-term objectives.

It is uncertain, however, whether the availability of customer information and measurability of customer-specific and long-term objectives will bring retailers and manufacturers any closer; on the one hand, the new customer-focused approach introduces retailers to a typically industrial way of reasoning customer-focused objectives - while the appreciation of intrabrand, interbrand, intracategory and intercategory effects broadens the manufacturer's view of the market, by definition narrower than that of the retailer. From this viewpoint, then, the two marketing visions might move closer. On the other hand, retailers' objectives are different from those of manufacturers' - consider the motivation to sell a range, rather than specific brands, to retain best customers, or to expand share of wallet; once retailers are better enabled to measure such objectives, they will select promotions accordingly, refusing to run and cooperate on promotional activities that hamper fulfilment of their own goals. A clearer vision of promotional results can shake long-established partnerships and conflict might become 
harsher. Research is therefore needed to further explore the impact of improved promotional measurement on vertical relationships.

\section{CONCLUSIONS AND STIMULI FOR FURTHER RESEARCH}

Research on retailers' use of loyalty card information across Europe began several years ago. Today, evidence shows that, on the one hand, retailers declare that customer information is vital for competitive advantage; on the other hand, they hesitate to put data to any use. ${ }^{7,8}$ Retailers are seeking ways to make loyalty investments pay for themselves: in the literature, at least, there seem to be many attractive options. With the often cited exception of Tesco in the UK, however, applications of individual customer information in retailing are rather conservative, limited to improving and running the loyalty scheme, direct communication and location analysis, as found by the survey of the Italian market in 2003 and confirmed on a European scale. ${ }^{9}$ Several avenues are still to be explored, where scope for value creation exists, such as segmentation based on shopping baskets, ranging stores differently, new product/service development, cross-selling across channels.

In order to move from mass to information-intensive marketing, however, retailers should not dissipate their efforts in many directions, but focus on a few priority areas of intervention, depending on their marketing mix and competitive position. This paper suggests that one such area is the measurement of promotional effectiveness, and the consequent improvement of promotional decisions.

The following points emerging from the research would benefit from further exploration:
- Promotions drain increasing amounts of financial resources and become more complex, while their returns are diminishing; retailers and manufacturers will therefore strive for ways to improve effectiveness and to obtain additional resources by making loyalty investments pay for themselves.

- At the same time, the retention culture and the availability of individual customer information bring customer-specific promotional objectives to marketers' attention, urging them to rethink generic sales lift goals.

- The discovery of customer heterogeneity and the ability to carefully segment and target the customer base, coupled with efficient direct media such as e-mail, SMS and electronic coupons, create conditions to expand the variety of promotional tools and actions.

- In this scenario, a customer-focused approach - as opposed to the current product-focused perspective increases the possibility of measuring promotional effectiveness in three dimensions:

- objectives, in that not only sales volume and market share effects can be tracked, but also increasingly important customer-specific ones (supplier viewpoint) and assortment-wide ones (retail viewpoint);

- time, in that promotional effects can be traced for longer periods of time and the fulfilment of long-term goals can be measured;

- space: thanks to geo-marketing analysis, sense can be made of the variability of promotional response in different retail markets, channels and outlets.

- One could argue that consumer panel research such as Nielsen Home scan can serve the same purpose but, 
generally speaking, such panels are designed to answer

manufacturer-specific questions regarding promotions, are based on statistical generalisation and, in markets such as Italy, where the retail market is highly fragmented, only a few retailers can find answers regarding their own customer base in the panel. Most banners go unrepresented. Finally, panel information cannot be used directly for targeting one's own customer base.

- Such expanded possibilities will have an impact on vertical relationships: improvements in the three areas above reverberate on the retailer's promotional decision-making process, affecting choice of category, brand, timing and partner manufacturer for promotions. As a result, the conflict/cooperation balance in the retailer's relationship with suppliers can change. It is likely that, in the future, a retailer's evaluation of prospective partners will incorporate elements such as ability to discuss and set customer-specific and long-term objectives. Manufacturers who are quick to adopt the new language of promotions and are willing to incorporate customer-specific and assortment-wide objectives and ex-post measures in their promotional agreements (and also category management agreements) with retailers might gain an advantage.
- The expansion of promotional experimentation and variety, however, is likely to be limited by cost factors, complexity of promotional plan management, shortage of marketing analysis skills, cultural factors such as the long-established practice of entitling buyers, not the marketing function (where knowledge about customers resides), to decide which manufacturer's promotional proposal to accept.

\section{References}

1 Bell, D. R., Chiang, J. and Padmanabhan, V. (1999) 'The decomposition of promotional response: An empirical generalisation', Marketing Science, Vol. 18, No.4, pp. 504-526.

2 Raghubir, P., Inman, J. J. and Grande, H. (2004) 'The three faces of consumer promotions', California Management Review, Vol. 46, No. 4, pp. 23-42.

3 Hawkins, G. (1999) 'Building the customer specific retail enterprise', Breezy Heights Publishing, New York, NY.

4 Ziliani, C. and Bellini, S. (2005) 'Le ciblémarketing en Italie: Tendances et prévisions de développement', Revue Française de Marketing, Vol. 203, Juillet, pp. 3-5.

5 Busacca, B. and Mauri, C. (1994) 'L'efficacia dell'azione promozionale al consumo', Finanza, Marketing e Produzione, No. 3, pp. 45-84.

6 Ziliani and Bellini (2004) op. cit.

7 Cuthbertson, R. and Laine, A. (2004) 'The role of CRM within retail loyalty marketing', Journal of Targeting, Measurement and Analysis for Marketing, Vol. 12, No. 3, pp. 290-304.

8 Stone, M., Bearman, D., Butscher, S. A., et al. (2004) 'The effect of retail customer loyalty schemes - Detailed measurement or transforming marketing?', Journal of Targeting, Measurement and Analysis for Marketing, Vol. 12, No. 3, pp. 305-18.

9 Cuthbertson and Laine (2004) op. cit. 